\title{
SOCIEDADE MODERNA: CIÊNCIA E SENTIDO EM ERIC WEIL
}

\author{
Daniel Benevides Soares ${ }^{1}$ \\ Universidade Federal do Ceará (UFC) \\ https://orcid.org/0000-0001-7275-9217 \\ E-mail: benevides.soares@gmail.com
}

\section{RESUMO:}

A sociedade moderna weiliana se caracteriza entre outras coisas pela sua sua concepção de ciência. Ambas fundadas no princípio do cálculo eficaz, a compreensão de seu funcionamento e de suas limitações caminham juntas. Assim, analisar a sociedade moderna contempla uma discussão da instância que funciona como sua autoconsciência: a concepção de ciência que lhe é própria, as ciências sociais, cuja matriz é a ciência da natureza. Ciência e sociedade moderna são compreendidas no âmbito da categoria weiliana da condição. Aqui não existe apelo a um princípio incondicionado. Desse modo, a questão do sentido não pode ser feita. Não se trata com isso de renunciar às conquistas da ciência moderna. Na visão de Weil, entretanto, deve-se reconhecer que a questão do sentido pode ser feita adequadamente. Isso porque ela deve ser posta pela filosofia. Nosso objetivo no presente trabalho é discutir a relação entre sociedade moderna, ciência moderna e o sentido. Isso porque se existe uma ciência de uma sociedade eficaz também existe uma ciência do sentido: essa é a filosofia.

PALAVRAS-CHAVE: Eric Weil; Sociedade; Ciência; Sentido.

\section{MODERN SOCIETY: SCIENCE AND SENSE IN ERIC WEIL}

\begin{abstract}
:
Eric Weil's modern society is characterized among other things by its conception of science. Both based on the principle of effective calculation, the understanding of its functioning and its limitations go together. Thus, analyzing modern society contemplates a discussion of the instance that functions as its self-consciousness: the conception of science that is its own, the social sciences, whose model is the science of nature. Modern science and society are understood within the scope of the Weil's category of condition. Here there is no appeal to an unconditioned principle. Therefore, the question of sense can not be made. However, it is not a question of renouncing the achievements of modern science. In Weil's view, however, it must be recognized that the question of sense can be properly made. This is because it must be put through philosophy. Our objective in the present paper is to discuss the relationship between modern society, modern science and sense. This is because if there is a science of an efficacius society there is also a science of sense: this is philosophy.
\end{abstract}

KEYWORDS: Eric Weil; Society; Science; Sense.

\footnotetext{
${ }^{1}$ Doutor em Filosofia pela Universidade Federal do Ceará (UFC), Fortaleza - CE, Brasil.
}

SOARES, Daniel Benevides. Sociedade moderna: ciência e sentido em Eric Weil. Griot : Revista de Filosofia, Amargosa-BA, v.19, n.2, p.171-181, junho, 2019. 
Nosso propósito é discutir a relação entre sociedade e ciência modernas e o sentido no pensamento de Eric Weil. Para esse objetivo, organizamos nosso trabalho em três momentos. No primeiro, apresentamos sinteticamente a análise weiliana da sociedade moderna. Em seguida, descrevemos de modo sucinto a visão de ciência própria da modernidade. Traçados esses dois objetivos, finalmente, apontamos a insuficiência dos conceitos abordados nos dois primeiros momentos para a problemática do sentido. Feita essa breve apresentação do nosso plano expositivo, passemos à sociedade moderna weiliana.

\section{A sociedade moderna}

É difícil fixar uma data precisa para o nascimento da modernidade, bem como atribuir-lhe uma só paternidade. Não obstante, pode-se considerar que a filosofia começa a ser moderna a partir do momento em que adquire uma consciência histórica dela mesma e uma consciência filosófica de sua história (KIRSCHER, 1992, p. 75). Weil se serve várias vezes do adjetivo "moderno": Estado moderno, trabalho moderno, técnica moderna, pensamento moderno, sociedade moderna. Weil designa assim um conjunto de determinações precisas, de características positivas e específicas, aplicadas, sobretudo, aos campos da política, da sociedade e do Estado (KIRSCHER, 1992, p. 77 - 78). Nosso objetivo é lidar com a segunda. Sociedade para Weil é a organização do trabalho social, ou organização de uma comunidade histórica na sua luta contra a natureza exterior, violência primeira ou violência exterior. "Por sociedade, entende-se a comunidade dos indivíduos ligados entre si por relações cotidianas de trabalho e de troca" (CANIVEZ, 1991, p. 16). Podemos ainda acrescentar mais uma definição: homens trabalhando em comunicação por meio da linguagem. Disso podemos extrair que as formas de trabalho se especificam em função das formas de linguagem. Isso também ocasiona a distinção entre tipos de sociedade (CANIVEZ, 1999, p.145).

Numa sociedade tradicional a linguagem possui uma função de transmissão, de saberes e ritos, de técnicas e modos de organização que pouco variam. A luta contra a violência da natureza (do clima, das catástrofes, da necessidade) é defensiva, estática (CANIVEZ, 1999, p.145-146). O trabalho na sociedade moderna se alicerça na linguagem do cálculo racional. Aqui a luta contra a natureza é ofensiva e progressiva, pois se trata de angariar maestria sobre a natureza, dominado-a. A linguagem se presta à elaboração não somente de uma técnica, mas de uma tecnologia, pois ela não apenas transmite procedimentos, mas os modifica conscientemente por uma busca calculada da performance. Nessa conjuntura, a busca por uma eficácia cada vez maior se reflete nos métodos de organização do trabalho. A linguagem da racionalidade positiva representa a base da sociedade, muito embora ela apresente suas limitações. As principais características da sociedade moderna seriam então: trabalho calculado em vista de uma eficácia progressivamente maior, linguagem da racionalidade científica, valores centrais do progresso e da utilidade (CANIVEZ, 1999, p.146).

A sociedade moderna também se caracteriza como um mecanismo de troca e produção, um sistema de funções sociais hierarquizadas em razão de sua importância no conjunto do mecanismo social. As funções sociais são conectadas de modo 
desigual tanto aos benefícios do trabalho (retorno financeiro, tempo livre, etc.) quanto em relação ao poder sobre o conjunto da sociedade. É à lei positiva, ou direito civil, que cabe a incumbência de catalogar as diferentes funções e regular os variados papéis sociais (CANIVEZ, 1999, p.146-147). A categoria ${ }^{2}$ que representa a sociedade organizada do trabalho é a condição. Ainda de acordo com o autor, a modificação dos mecanismos injustos dessa sociedade empreendida politicamente segundo objetivos éticos passa pela compreensão do agir político explicitado por sua vez na categoria da ação (CAMARGO, 2014, p. 50).

A condição ocupa o lugar de atitude característica da modernidade por ser a mais difundida e a mais natural, representando a consciência média nesse período presente no homem da sociedade industrial (PERINE, 1987, p. 181). Assim sendo, podemos dizer que a condição é a primeira e decisiva categoria da modernidade propriamente dita, constituindo a âncora e o solo das convicções do homem moderno. Sua racionalidade é a operatória, dada à imanência de um mundo reduzido a uma rede homogênea de relações mensuráveis. A condição oferece, com suas capacidades de domínio e maestria sobre a natureza, uma guinada radical em relação à teoria clássica, afeita a uma ordem hierárquica que visava uma contemplação desinteressada (GUIBAL, 2011, p. 121). O mundo da condição é mundo organizado. O homem aí é o lugar que nele se ocupa na sociedade onde acontece o embate pela satisfação. A sociedade aparece na condição como pseudo natureza, distinta da própria natureza, mas que é tão hostil e ameaçadora quanto a primeira (PERINE, 1987, p. 181).

O caracteriza uma civilização como moderna é a presença do conceito de história. Deste modo, é moderna a civilização que apresenta uma historiografia, que se afirma como sujeito e constitui na sua autobiografia, que supõe que existem eventos novos e decisivos, históricos, e não somente a repetição de uma ordem de mundo intemporal (KIRSCHER, 1992, p. 103). Dito isso, convém pontuar que nem todas as civilizações contemporâneas são modernas, pois existem graus de modernidade. Como exemplo, os gregos, com sua concepção cósmica e cíclica do curso dos eventos - cosmos e eterno retorno - seriam menos modernos que a civilização judaico-cristã com sua concepção linear de tempo (KIRSCHER, 1992, p. 104). O último grau da modernidade ${ }^{3}$ é o processo de secularização que desloca uma ordem religiosa por uma ordem política e que substitui uma ordem metafísica por

\footnotetext{
$2 \mathrm{Na}$ lógica do discurso weiliano, nós encontramos uma possibilidade lógica e uma possibilidade real. A possibilidade lógica é a categoria. Ela é uma forma de coerência que define umas das possibilidades do discurso. Mas a cada possibilidade lógica corresponde uma possibilidade real: a atitude. Trata-se aqui daqueles que de fato vivem no e pelo discurso. Para aqueles que existem na atitude, a referida categoria constitui o conceito central no qual se organiza sua ligação com o mundo e consigo mesmo (CANIVEZ, 1999, p.32).

${ }^{3}$ Para Weil, duas idéias foram importantes para explicar a origem da sociedade moderna. A primeira é a noção de igualdade dos homens como seres razoáveis, o que possibilita o conceito de uma verdade acessível e válida para todos, elemento presente no estoicismo e no cristianismo. A segunda idéia é a de uma ciência da natureza exata, que procede por descrição e análise, não sendo explicativa no sentido de utilizar-se de narrativas ou histórias. Desse modo, a natureza passa a ser encarada como objeto da razão. Esse último pensamento, por sua vez, deve sua origem a três outros. O primeiro é a noção judaico-cristã de um Deus criador que, embora mantenha fins insondáveis, age racionalmente. Em segundo lugar, encontra-se a idéia platônica de um cosmo que é eterno, ordenado e matematizável. Finalmente, encontra-se a noção de unicidade e uniformidade da natureza que, por sua vez, é apreensível a partir de fenômenos terrestres; uma contribuição do epicurismo. O encontro de tais idéias e sua fusão sistemática foi responsável por modificar a forma de se lutar com a natureza. Isso porque, para Weil o modo natural de enfrentamento da natureza exterior é defensivo e estático (CAMARGO, 2014, p. 140).
} 
uma ordem filosófica de outro feitio - mudança do cosmos metafísico pela natureza da física-matemática (KIRSCHER, 1992, p. 104 - 105). Essa guinada de perspectiva dá origem a uma nova concepção de natureza.

A sociedade moderna se entende como lidando com uma natureza exterior hostil, violenta, em luta contra uma realidade estrangeira. Já uma sociedade mágicoreligiosa não tem um outro que lhe seja exterior, posto que se considera como participando de um mundo cuja ordem ela assegura pela observação ativa e rigorosa dos ritos sem os quais a vida seria impossível (KIRSCHER, 1992, p. 78). Para a sociedade moderna a natureza é a totalidade de matérias-primas que o homem transforma e das leis particulares e parciais do seu funcionamento, cujo conhecimento possibilita a transformação (WEIL, 2011, p. 82). Essa mudança no modo de considerar a natureza - de sensata em si mesma, segundo a ótica do pensamento tradicional, para matéria-prima e realidade material - está na origem da nossa sociedade (WEIL, 2011, p. 118).

Uma sociedade tradicional mágico-religiosa integra a vida humana em um mundo pleno de sentido. A sociedade moderna caracteriza-se pela relação entre sujeito agente versus um universo de objetos à sua disposição. A natureza exterior não é mais percebida sob categorias metafísicas ${ }^{4}$ dignitárias de respeito cujo curso seria impiedade perturbar: cosmos, belo, divino. Para essa sociedade, somente o trabalho progressivamente mais eficaz é verdadeiramente trabalho (KIRSCHER, 1992, p. 80 - 81). Eis a definição que Weil oferece dessa sociedade:

[...] a sociedade moderna mostra-se calculista: toda decisão, toda transformação dos processos de trabalho e de organização, todo uso das forças disponíveis (humanas e naturais) deve ser justificado demonstrando que o domínio do homem sobre a matéria é reforçado, dito de outro modo, que o mesmo resultado mensurável é obtido com menor dispêndio de energia humana, ou que uma quantidade maior de forças naturais é posta à disposição da humanidade (ou da comunidade particular), o que não seria possível com métodos anteriores. A sociedade moderna é materialista porque nas suas decisões só os fatores materiais são levados em consideração. Ela é mecanicista porque todo problema deve ser transformado em problema de método de trabalho e de organização, e só deve referir-se ao mecanismo do trabalho social: todo problema que não pode ser formulado assim é, por definição, um falso problema (WEIL, 2011, p. 87).

Essa sociedade é dita materialista, mecanicista e calculista, não por estar baseada em teorias e convicções de ordem materialista, mas sim porque apenas fatores dessa ordem estão agindo. Esse é o aspecto exclusivo da sociedade que as ciências sociais descrevem adequadamente (CAILLOIS, 1977, p. 4).

\footnotetext{
${ }_{4}^{4}$ Em Weil as categorias são conceitos fundamentais em torno dos quais se organizam as diferentes formas possíveis de coerência, cada uma constituindo uma das possibilidades fundamentais do discurso coerente. Essas categorias weilianas, não são categorias na acepção habitual que designa substância, causa, etc.; não são categorias metafísicas e sim filosóficas. As primeiras, também tomadas como meta-científicas, são aquelas pelas quais a filosofia dá conta da possibilidade ou atividade da ciência. Já as categorias filosóficas são formas do discurso que definem os pontos de vista logicamente possíveis sobre o real. As categorias metafísicas têm lugar nas categorias filosóficas, de modo que o emprego e o sentido das categorias metafísicas variam de acordo com a categoria filosófica no seio da qual cada uma delas aparece (CANIVEZ, 1999, p. 35).
} 
Convém acrescentar ainda que originalmente o sentido do termo 'organização' vem do 'organismo' enquanto indicativo de um tipo característico de uma espécie particular de ser vivo. Já na perspectiva moderna, no contexto da organização social, o termo considera sobretudo - mas não exclusivamente - uma sistematização artificial com vistas a fins. Trata-se da estrutura dessa sistematização; evoca-se, portanto, a idéia de cálculo e técnica de organização (WEIL, 2011, p. 167 - 168). Essa concepção de sociedade pede, em conjunto com sua análise, uma apresentação de sua ciência, moderna como ela própria.

\section{A ciência moderna}

Podemos entender a ciência moderna como um sistema de proposições desenvolvido segundo certas regras. Sistema, por sua vez, indica que cada proposição da ciência deve ser compatível com todas as outras e que cada dado descoberto pode ser descrito por essa ciência e incorporado no seu conjunto. Essa definição, contudo, dá conta de um ideal de ciência, pois o que existe na realidade são ciências - física, química, biologia -, ou seja, conhecimentos organizados em certo domínio (WEIL, 1970 , p. 354 - 355). Podemos acrescentar que a ciência moderna ${ }^{5}$ também é a organização dos dados da observação por meio de uma análise que, descobrindo fatores escondidos, explica servindo-se deles, a regularidade dos fenômenos (WEIL, 2011, p. 19). Essas características são compartilhadas por todas as ciências modernas que se pretendem objetivas, ou seja, funcionando em analogia com as ciências naturais, o que é o caso das ciências que expressam a autoconsciência da sociedade moderna $^{6}$ : as ciências sociais.

$O$ arquétipo de toda ciência verdadeira é a física, paradigma copiado por todas as demais ciências e tecnologias: ciências biológicas, ciências sociais, sociologia histórica. Todas aspiram à objetividade com o único fito de atender à maestria já alcançada pela ciência-modelo. O propósito é o sucesso, desvelando suas condições necessárias, prevendo consequências. Analisando conjunturas econômicas e sociais, busca-se dirigir o curso dos eventos (WEIL, 1970, p. 276 - 277).

Em si mesma, a ciência moderna é teoria pura, ou seja, objetiva, rejeita o antropomorfismo e antropocentrismo. Herdeira da ideia grega da verdade como sistema de discurso coerente, apresenta, entretanto, uma distinção importante. Não está presente a ideia de que o conhecimento do mundo conduz o homem ao conhecimento de si mesmo, indicando-lhe a melhor maneira de viver. A ciência moderna não admite a ideia de um mundo sensato e que possa ser compreendido à maneira do cosmos grego (WEIL, 1970, p. 280). A natureza para o físico é aquilo que o universo humano e histórico é para as ciências sociais: estruturas e fatos que são passíveis de descobertas, sem que, entretanto, um sentido vinculante que possa ajudar o historiador, o economista e o etnólogo a conduzirem suas vidas particulares. Toda significação que as estruturas contêm para seus habitantes não passam de fatos para as ciências sociais (WEIL, 1970, p. 280 - 281).

5 A ciência moderna aparece ao longo do século XVII e a tecnologia a acompanha não sem certa lentidão. É apenas a partir de 1780 que a industrialização de tipo moderno começou, expandindo-se pouco a pouco, ao mesmo tempo que a competição entre as nações engaja-as individualmente e no seu conjunto nos processos históricos dos séculos XIX e XX (DUBARLE, 1970, p. 527 - 528).

${ }^{6}$ Cf. WEIL, 2011, p. 99.

SOARES, Daniel Benevides. Sociedade moderna: ciência e sentido em Eric Weil. Griot : Revista de Filosofia, 
A partir dessa afirmação podemos extrair e desenvolver duas considerações. Em primeiro lugar, devemos considerar que a sociologia teórica descreve adequadamente a sociedade moderna por trabalhar conforme a perspectiva segundo a qual essa sociedade enxerga a si mesma e que, igualmente, quer para si. Devemos considerar também que o valor principal para ela é uma paz social alicerçada no valor da eficácia, esta entendida como progresso, rendimento, nível de vida, riqueza social $^{7}$. Dizer que a sociologia teórica persegue a paz social deve ser entendido da seguinte maneira: “[...] não há eficácia sem paz social; esta deve ser estabelecida para que o mecanismo econômico possa encarregar-se do resto e produzir com o máximo de eficácia" (WEIL, 2011, p. 88).

A paz social é a condição para a produção eficaz. Em segundo lugar, partindo do pressuposto que as ciências sociais teóricas trabalham com um conceito fundamental de organização eficaz, oriunda de uma sociedade que se quer racional, podemos então compreender que ciências sociais e sociedade, ambas modernas, estão fundadas no mesmo princípio. Portanto, a descrição que as primeiras fazem da segunda é adequada. É desse modo que compreendemos a nossa afirmação de que essas ciências representam a autoconsciência da sociedade. Isso significa que as ciências sociais compreendem-se a partir do princípio particular da sociedade moderna $^{8}$. "Só uma sociedade racionalista e mecanicista pode querer se compreender numa ciência, isto é, numa análise calculista, numa descrição que não admite outro critério além da calculabilidade, em vez de se compreender num sistema de valores múltiplos e coordenados ou a coordenar [...]" (WEIL, 2011, p. 88). Esse princípio que é comum tanto à sociedade moderna quanto à sociologia teórica que a descreve, toma a primeira na conta na conta de um dado análogo à natureza exterior. Consequentemente, as análises das ciências sociais seguem os mesmo métodos das ciências naturais, visando, mediante fatores e previsões verificáveis, uma análise funcional ${ }^{9}$.

\footnotetext{
Não foi por acaso que a sociologia nasceu depois da economia política e que esta constitui a parte mais avançada da ciência social: a grande descoberta do século XVIII foi ter visto que o trabalho social pode ser analisado em analogia com a natureza, concebida como mecanismo, e que, por conseguinte, a intervenção do homem (do Estado) deve primeiro respeitar as leis da economia, que delineiam o quadro da sua ação, assim como as leis da natureza traçam o quadro da ação do técnico (WEIL, 2011, p. 88).
}

As ciências sociais buscam o conhecimento das condições sociais. Trata-se de uma ciência que, como tal, enxerga-se como praticada por um observador-analista que se propõe uma descrição e análise pautadas pela objetividade (WEIL, 2011, p. 19 - 20). Elas têm por finalidade tornar previsível o resultado de uma intervenção. Para tanto, devem submeter suas teses a um critério determinante: a coerência entre seus ensinamentos e prescrições e o sucesso prático das suas experiências (WEIL, 2011, p. 90).

\footnotetext{
${ }^{7}$ Cf. WEIL, 2011, p. 87 -88.

${ }^{8}$ Cf. WEIL, 2011, p. 88.

${ }_{9}$ Cf. WEIL, 2011, p. 87 -88.
}

SOARES, Daniel Benevides. Sociedade moderna: ciência e sentido em Eric Weil. Griot : Revista de Filosofia, 
O seu método funda-se na estatística matemática, utilizada com o intuito de estabelecer os fatores de interdependência que são alvo da pesquisa (WEIL, 2011, p. 91).

\begin{abstract}
A relação entre estatística, observação e experimentação, nestas ciências, é análoga à que existe nas ciências naturais: o material observado é submetido a uma descrição estatística, o que conduz a uma análise mediante fatores e interdependências; esta permite novas observações e experiências, feitas em virtude de uma primeira teoria matemática; daí procede-se à criação de modelos conceptuais sempre mais coerentes e sempre mais aptos para analisar exaustivamente um material cada vez mais plenamente dominado (WEIL, 2011, p. 91).
\end{abstract}

Nas ciências naturais não se trata de estabelecer uma predição, mas sim de analisar um certo número de eventos de um mesmo tipo a fim de estabelecer uma estatística para, então, apontar qual seria a probabilidade dos resultados (WEIL, 2011, p. 92).

O mesmo acontece nas ciências sociais: que $X$ pessoas a cada ano se suicidem numa comunidade não permite perguntar se o Senhor $\mathrm{X}$ morrerá assim; que em centenas de casos observados os homens decidam-se sob a influência de motivos religiosos, econômicos, etc. não permite predizer se um sujeito, numa situação concreta, vai se decidir segundo determinado motivo (WEIL, 2011, p. 92).

Finalmente, graças as regularidades descritas na forma de leis sociais os indivíduos tomam a sociedade na conta de algo que se pode conhecer e influenciar, assim como a ciência natural descobre as leis de funcionamento da natureza, as leis sociais que descrevem o funcionamento da sociedade a convertem, para o indivíduo, em segunda natureza (WEIL, 2011, p. 92).

Feita essa apresentação das ciências modernas, podemos agora apontar o que constitui algumas de suas limitações. Vamos a elas.

Em primeiro lugar atentamos para a irrevogável presença de uma equação pessoal na constituição do observador-analista que é o cientista. Essa indelével assinatura, diz Weil, não tenciona contestar a validez ou mesmo a objetividade das observações do homem de ciência, especialmente do dedicado à ciência social, apenas, do ponto de vista do seu sistema, demonstrar a impossibilidade de reduzir a ação a uma coisa que é diferente da própria ação, posto que é nela que reside o ponto de vista e a finalidade em função das quais se dá o horizonte de conhecimento e compreensão das ciências modernas (2011, p. 20). As pesquisas das ciências sociais, na medida em que são objetivas, não têm como distinguir o problema essencial dentre aqueles que não são mais do que os que lhes chegam (DOUMIT, 1970, p. 511 - 512). As ciências, portanto, não se compreendem a si mesmas e não são compreensíveis em si mesmas, o que, salienta Weil, não impede que elas sejam praticadas sem compreensão (2011, p. 19 - 20). Consequentemente, as ciências exatas, naturais e sociais dizem respeito ao conhecimento, não a compreensão do mundo no qual os homens se situam, de modo que não permitem os meios para justificar decisões fundamentais. 
A série de discursos científicos da condição não considera nada que não seja susceptível de racionalização objetiva (GUIBAL, 2011, p. 123). A rede contínua de condições é incapaz de se compreender ela mesma, bem como as condições e a significação de sua emergência histórica. Sua racionalidade não é capaz de pôr em questão problemas relativos ao fundamento, a essência ou ao sentido (GUIBAL, 2011, p. 123). Assim sendo, a condição apresenta duas consequências, uma no plano teórico e outra no plano prático. No plano teórico ela não permite um conhecimento de si. No plano prático, engaja o indivíduo em um frenesi niilista incapaz de orientação razoável (GUIBAL, 2011, p. 127).

Podemos a essa altura trazer de volta a discussão a respeito da sociedade moderna para compreendermos o quanto ela encontra-se em conexão umbilical com a ciência que nos ocupou agora.

A noção de mecanismo social pressupõe a noção mais fundamental de mecanismo geral. Dito isso, o princípio da modernidade poderia ser anunciado da seguinte maneira: a realidade, seja ela qual for, é estruturada como um mecanismo. A noção de mecanismo e inicialmente imposta e edificada na elaboração das ciências matemáticas da natureza, sendo, em seguida aplicada pelas ciências sociais ao seu domínio particular: a sociedade (KIRSCHER, 1992, p. 82). E é precisamente a idéia de mecanismo natural que preside o nascimento da época moderna. Sob essa perspectiva, é possível pensar que sociedade moderna e as ciências sociais são consequências da verdadeira fundação da civilização moderna: a ciência moderna da natureza (KIRSCHER, 1992, p. 82).

A idéia de natureza trazida pela ciência moderna é um objeto novo. Cosmos antigo e natureza moderna são duas interpretações, duas idéias, dois objetos de ciência radicalmente diferentes. Se a ciência antiga se interpreta como pura contemplação daquilo que é e do princípio daquilo que é, a ciência moderna não concebe a natureza como puro espetáculo (KIRSCHER, 1992, p. 83). A ciência moderna descreve seu objeto em uma linguagem matemática que, para além de medidas e relações entre medidas, nada conhece ou seja, não há mais espaço para qualquer qualidade não quantificável (KIRSCHER, 1992, p. 85).

O mundo moderno, segundo Kirscher, é caracterizado como essencialmente em crise. Isso significa que ele não é mais um cosmos e, sendo assim, cada função social não tem outro valor reconhecido para além de sua função, de modo que a idéia de um impedimento que não seja apenas uma limitação técnica, a idéia de um valor em e por si, que daria sentido à vida e à realidade, tais idéias aparecem mais e mais desatualizadas, como os vestígios de um pensamento ultrapassado pela modernidade (1992, p. 274). A ciência e técnica modernas, da condição, são destituídas de sentido. Sua única finalidade é adquirir a capacidade e os meios de continuar seu trabalho e se perpetuar a ela mesma (KIRSCHER, 1989, 268).

A atitude da condição se opõe a qualquer busca pelo sentido, substituindo-a pelo enriquecimento científico e material. Assim, questões pessoais - preocupações morais, estéticas e religiosas, bem como as filosóficas são tomadas como invenções de romancistas - tidas, na conta de epifenômenos que devem apenas ser explicados em sua origem histórica para que sejam tratados e não possam aspirar a nenhuma influência legítima sobre os trabalhadores (WEIL, 2012, p. 313). A questão do sentido perde a importância assim como toda reflexão que não serve ao progresso do 
trabalho. Isso porque natureza para a ciência da condição não é mais cosmos; natureza é o que condiciona o homem e é condicionada por ele. O que existe é a luta contra essa natureza com o único fito de satisfazer necessidades e desejos que são parte ou derivados dessa natureza, necessidades e desejos que são apenas condições condicionadas. Para o homem que vive na atitude da condição, termos como felicidade e salvação só são tomados na perspectiva da pergunta pelas condições que possibilitaram o surgimento dessas idéias (WEIL, 2012, p. 290 - 291).

\begin{abstract}
Todos os sistemas metafísicos, todos os pensamentos que quiseram ultrapassar a ciência da natureza levaram a discussões sem-fim, a lutas, perseguições, turbulências. Se o homem não pode renunciar a esse jogo, que não o leve a sério! Que se diga que são sonhos, todos equivalentes entre si! Não seria duplamente absurdo que ele sacrificasse seu interesse humano, o progresso, a quimeras que não defendem nem mesmo vantagens reais? A tirania é útil ao sacerdote e ao nobre, sem dúvida, mas o que o metafísico extrai de sua renúncia aos bens deste mundo? Joguemos, se não conseguimos nos abster disso, e deixemos jogar os outros; mas não perturbemos a paz com discussões vãs. Virá o dia em que a ciência descartará ou resolverá esses problemas ao lhes dar um sentido preciso. Até lá, trabalhemos (WEIL, 2012 A, p. 307).
\end{abstract}

Nessa conjuntura, os argumentos éticos são substituídos por argumentos comerciais e técnicos. Como exemplo, temos a biologia, cujas realizações são pautadas, antes de mais nada, pelas possibilidades técnicas. Nesse contexto, os efeitos das ciências são sentidos na construção da sociedade. A biologia torna-se capaz de interferir na ordem humana. A física, por seu turno, reduziu o cosmos do mundo antigo a um mecanismo destituído de um fim último, de um sentido. Aqui, nenhuma orientação será mais possível por não se tratar, na modernidade, mais de mundo, mas de um campo de forças físicas, objeto de uma ciência racional e positiva da realidade. Entretanto, essa ciência é incapaz de pôr a questão do sentido e e da orientação do homem no mundo. Essa questão é filosófica. (KIRSCHER, 1992, p. 274 - 275).

\title{
Insuficiência da ciência da condição enquanto autoconsciência da sociedade sob a perspectiva do sentido
}

A modernidade, então, suscita duas posturas diversas. De um lado, é possível simplesmente aquiescer e jogar o jogo da modernidade, aceitando essa racionalidade - e suas consequências - sem concessões. A segunda, é a posição oposta: trata-se de recusar totalmente essa racionalidade evocando uma nostalgia de tempos que eram melhores. Para o autor que nós acompanhamos nesse artigo, não se trata nem de uma de outra. Se não é possível abrir mão das conquistas da racionalidade técnica, também não é sensato fechar os olhos para as possibilidades de violência que ela inaugura. Ambas as posições, na verdade, apenas são empecilhos para que se coloque o problema do sentido: o problema filosófico da orientação no mundo (KIRSCHER, 1992, p. 276).

Enquanto civilização do trabalho organizado, a sociedade moderna torna-se indispensável para a existência do homem, mas não oferece nenhum sentido para sua 
vida (CAMARGO, 2014, p. 127). A dominação sobre a natureza e a história, proporcionada por suas respectivas ciências, não oferece um sentido para essa dominação (WEIL, 1970, p. 365). Desse modo, a questão do sentido é filosófica, distinguindo-se de uma perícia ou estudo científico. Isso aponta já para a impossibilidade de ser respondida, ou mesmo de chegar a ser colocada, pelas ciências da natureza, bem como por aquelas que operam em analogia com elas (KIRSCHER, 1992, p. 275).

Caso se considere que o ser humano vive em um mundo, não em meio a correntes de elétrons, que a humanidade é dotada de sentimentos e pensamentos, não sendo simples objetos da psicologia, fisiologia, da economia política e ciências sociais, a questão do sentido é posta claramente quando antes estava oculta, tão logo se reconheça que o ente humano nasce violento e pode continuar a sê-lo. A saída para a questão do sentido passa por uma análise da ação e dos discursos do homem que revelam o que é o mundo e que ele pode ser para ele mesmo. Trata-se de uma análise compreensiva da compreensão, que não é científica, mas da ordem da filosofia (WEIL, 1970 B, p. 295 - 296).

A filosofia é o discurso que compreende a si mesmo enquanto o discurso de um ser para o qual sempre permanece aberta outra possibilidade: a violência. Possibilidade essa realizada em primeiro lugar, o que significa dizer que o homem forma seu discurso na violência, contra a violência (WEIL, 2012, p. 104-105).

A filosofia não possui um domínio restrito, reservando-se o direito de falar de tudo segundo a lógica do diálogo (WEIL, 1970, p. 355). A filosofia não é uma ciência, pelo menos não conforme o feitio das ciências da observação e da experimentação. Não obstante, a filosofia é científica (WEIL, 1970, p. 357 - 358). A filosofia é científica eminentemente, ou seja, de modo diferente e mais profundo do que o das demais ciências particulares. Isso quer dizer que a filosofia é uma atividade que recomeça sem cessar, na qual cada tarefa rematada reenvia para uma nova a ser cumprida (WEIL, 1970, p. 365). Assim, a filosofia é científica eminentemente porque se recusa a ser uma ciência que se possa aprender na acepção das demais ciências, sendo na verdade uma interrogação sobre o sentido, sempre renovável, sempre a se renovar, pois não se contenta com as respostas dadas (WEIL, 1970, p. 367).

O sentido não está em um discurso em particular, presente de diversas maneiras sem que nenhuma seja absoluta. Ele encontra-se no jogo do movimento de transcendência imanente no mundo, no homem e no discurso. $O$ sentido formal se distingue da verdade por ser afirmação da verdade de um novo conteúdo, já que ele não possui conteúdo, e a verdade não é outra coisa que o preenchimento determinado do sentido formal (KIRSCHER, 1970, p. 394). O sentido é a forma da Lógica da Filosofia, a categoria na qual e sobre a qual vê-se toda atitude-categoria bem como ela própria (KIRSCHER, 1970, p. 377).

Filosofia é buscar o sentido, o sentido da filosofia e o sentido mesmo. Assim, nessa categoria se compreende o sentido daquilo que o homem fala, constrói, vive, e o sentido é mundo. Sentido é consciência filosófica da filosofia (QUILLIEN, 1981, p. 1230). Se a filosofia é ciência formal do sentido, é a linguagem que cria os sentidos concretos (QUILLIEN, 1981, p. 1233). Cabe a filosofia construir aquilo que a ciência moderna, capaz de erguer tantas coisas, é, não obstante, incapaz de oferecer. 


\section{Referências:}

CAMARgO, S. de S., Filosofia e política em Éric Weil: um estudo sobre a ideia de cidadania na filosofia política de Éric Weili. São Paulo: Edições Loyola, 2014.

CANIVEZ, P. Weil. Paris: Socié te d'édition les Belles Lettres, 1999.

CANIVEZ, P. Educar o cidadão? Campinas: Papirus, 1991.

CAILlOIS, R., Politique et violence chez Eric Weil. Revue de l'enseignement de philosophie, $28^{\circ}$ année, $\mathbf{n}^{\circ}$ 5, p. 1 - 10. Paris, 1977.

DOUMIT, E. Etat et société modernes dans la 'Philosophie politique'. Archives de Philosophie, $\mathrm{n}^{\circ}$ 33, p. 511 - 526. Paris: Beauchesne, 1970.

DUBARLE, D., Totalisation terrestre et devenir humain. Archives de Philosophie, $\mathrm{n}^{\circ}$ 33, p. 527 - 545. Paris: Beauchesne, 1970.

GUIBAL, F. Le sens de la rélité: logique et existence selon Eric Weil. Paris, Éditions du Félin, 2011.

KIRSCHER, G. Absolu et sens. Archives de Philosophie, ${ }^{\circ} 33$, p. 373 - 400. Paris: Beauchesne, 1970.

KIRSCHER, G. Figures de la violence et de la modernité: Essais sur la philosophie d'Eric Weil. Lille: Presses Universitaires de Lille, 1992.

KIRSCHER, G. La philosophie d'Eric Weil. Paris: Presses Universitaires de France, 1989.

QUILLIEN, J. De la sagesse comme fin de la Logique de la Philosophie: Sens et présence, poésie et philosophie. Annali della Scuola Normale Superiore di Pisa, volume XI, $\mathbf{n}^{\circ}$ 3, p. 1223 - 1242. Pisa, 1981.

PERINE, M. Filosofia e violência: sentido e intenção da filosofia de Éric Weil. São Paulo, Edições Loyola, 1987.

WEIL, E. Lógica da filosofia.. São Paulo: É realizações, 2012.

WEIL, E. Filosofia política. São Paulo: Edições Loyola, 2011.

WEIL, E. La philosophie est-elle scientifíque ? Archives de Philosophie, $\mathrm{n}^{\circ}$ 33, p. 353369. Paris: Beauchesne, 1970.

WEIL, E. Essais et conférences: tome I. Paris, Librarie Plon, 1970.

Autor(a) para correspondência: Daniel Benevides Soares, Universidade Federal do Ceará, Av. da Universidade, 2853 - Benfica, 60020-040, Fortaleza - CE, Brasil. benevides.soares@gmail.com 